\title{
Development of Automated Weather-Unaffected Building Construction System
}

\author{
Hideo Tanijiri, Bunya Ishiguro, Takashi Arai, Ryoji Yoshitake \\ Masao Kato, Yasuto Morishima, Nobuhiro Takasaki \\ New Production system Development Department, \\ Buildind Division, FUJTTA CORPORATION \\ 4-6-15 Sendagaya, Shibuya-ku, Tokyo, 151, JAPAN

\section{ABSTRACT}

An automated weather-unaffected building system has been developed which is aimed at creating a system for producing an attractive building system for the next generation. This system makes improvements with regards to problems pertaining to labor productivity, and creates a comfortable production environment for the new type of engineers of the future. It can provide high quality building at a low cost.

This system is based on the procedure that after the uppermost floor of the building is assembled on the ground level, various automated mechanical devices necessary for structural work are installed. The structural body of the building is constructed one floor at a time and each part in sequence under weather proof working conditions. Each is raised to the uppermost floor by means of a jack system. This paper reports the summary and execution of the above automated weather-unaffected building construction system.

\section{PREFACE}

An automated weather-unaffected building construction system has been developed, which aims at creating an attractive building production system for the next generation that can construct a high quality building at a low cost.

A group with the objective of developing the automated weather-unaffected building construction system was organized in 1991. A period of 2 years passed from 1993 to 1994 for the period of examination and planning of the system. Then a mock-up model was assembled and basic experiments were conducted to verify the performance

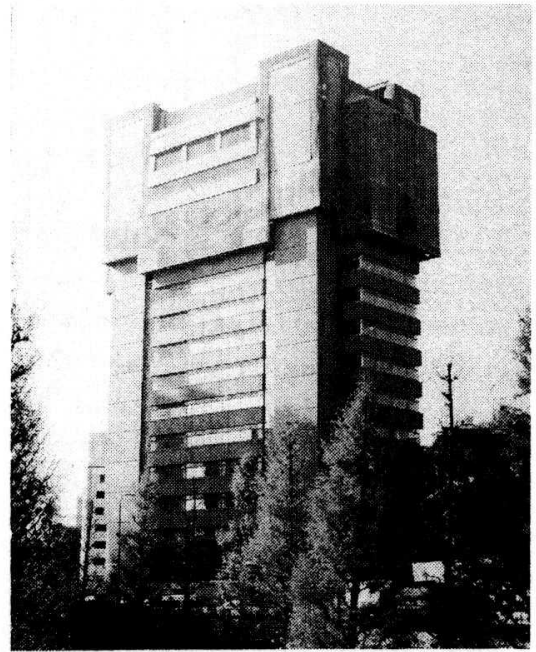

Photo 1. External appearance 
of the main automated machine device, which will form the basis of the system. From August 1995, the construction plan was applied to actual construction work which started in April 1995. Although the periods of time allowed for the construction plan, and that for the fabrication of the automated machine device, after the completion of the basic experiments to the starting of actual construction, were extremely short, the work has been progressing smoothly. This has been accomplished thanks to the support received form various organizations concerned, such as the many machine manufacturers and subcontractors including the owner and design office.

In this paper, the summary of the automated weather-unaffected building construction system and the circumstances of its application are the main subjects reported on.

\section{BASIC CONCEPT OF SYSTEM DEVELOPMENT}

The basic concept of system development, construction procedure and the composition of machine devices of the automated weather-unaffected building construction system are described below.

\subsection{BASIC CONCEPT OF DEVELOPMENT}

At the beginning of the development, the objectives of the improvement of the building production system and the predicted results were put together in the conceptual drawing as shown in Fig. 1, marking it as a basic concept in proceeding with the entire development.
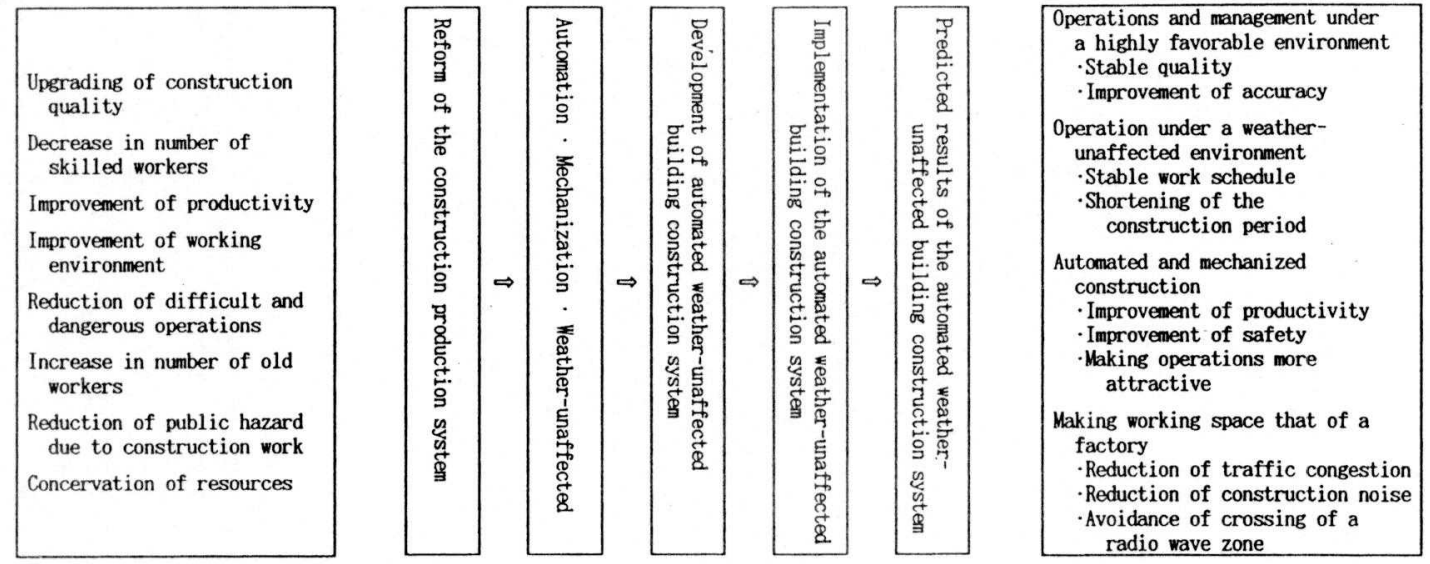

Fig. 1. Basic concept of the system development

\subsection{BASIC CONSTRUCTION PROCEDURE}

This system utilizes the basic construction procedure in which the uppermost floor of the building is structured at the ground level in order to begin with securing a weather-unaffected space. In this space, various machine devices for the automated construction of a building are installed and the building is made from first floor up in sequence, one floor at a time.

Fig. 2 shows the basic construction procedure of the system.

\subsection{BASIC COMPOSITION}

This system is composed of numerous newly developed automated machine 
devices. The plan was made for each machine device dividing the entire system roughly into 3 parts, as follows:

- factory in the air (hereinafter to be referred to as "sky factory")

- factory on the ground (hereinafter to be referred to as "ground factory")

- vertical automated conveyance line (hereinafter to be referred to as "transfer line")

The basic composition of the main machine devices that make up this system are shown in Fig. 3.

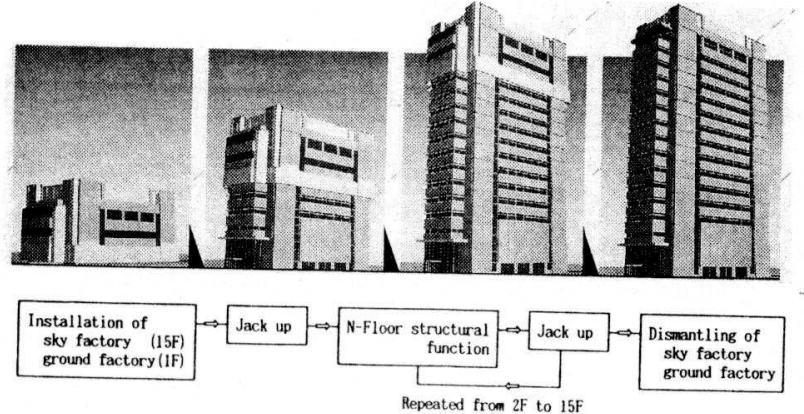

Fig. 2. Basic construction procedure

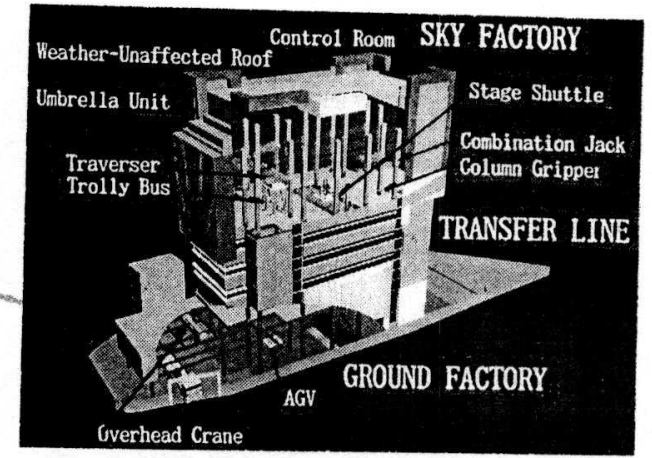

Fig. 3. Basic composition

3. SUMMARY OF THE WORK TO WHICH THE SYSTEM IS APPLIED

The summary of the work to which the system was applied is shown below. Fig. 4 shows the typical floor plan and Fig. 5 the total section.

Name of the work: Shuyo-dan Headquarters Building

Construction Work (Provisional)

: Sendagaya, Shibuya-ku, Tokyo

and Construction Supervision :

Execution : Fujita-Kajima Joint Venture

Construction : 1 storey underground (SRC),

$16 \mathrm{~F}$ aboveground $(\mathrm{S})$

Building area

Total floor area : $13,065 \mathrm{~m}^{2}$

Maximum height : GL +69.8 m

Construction period : March 15, 1994 to June 30, 1996 (including the demolition

Use work of an old building)

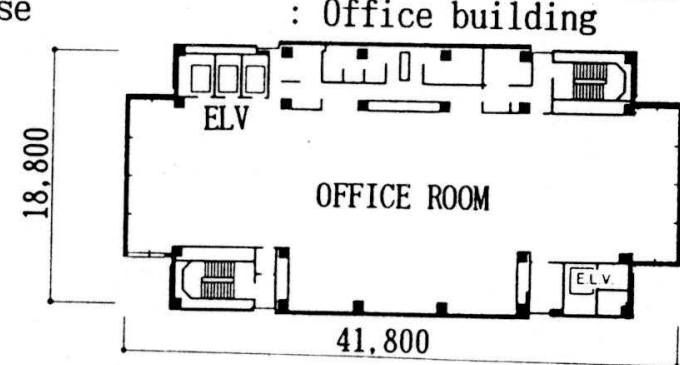

Fig. 4. Typical floor plan

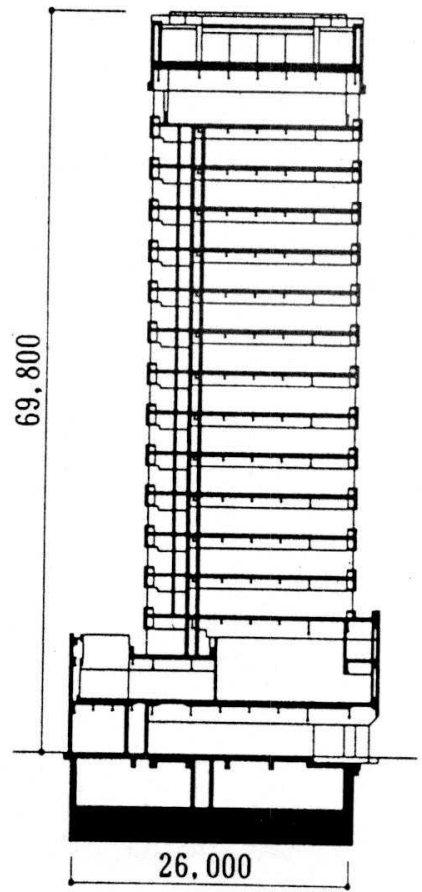

Fig. 5. Building Section 


\section{COMPOSITION OF THE DEVICES OF THE SYSTEM}

The machine devices that compose the ground factory, transfer line and sky factory as mentioned in 2.3, are described below.

\section{1 GROUND FACTORY}

The main roles of the ground factory include the role of a goods handling yard, where construction materials are moved in from outside and are quickly unloaded and reloaded to the vertical conveyor system which automatically supplies them appropriately to the servicing floor. Another role is that of a materials processing yard where construction materials are moved in, aiming at shortening the construction schedule by reducing the number of assembling steps in the sky factory.

The moving in of construction materials to the ground factory from outside, is accomplished through moving in gates provided at 2 locations, the south face and north face gates. The south face gate is used for the moving in of structural materials, such as structural steel, etc., and the north face gate is used for the moving in of finish materials.

Fig. 6 shows the layout of the ground factory, and the main component devices are described below.

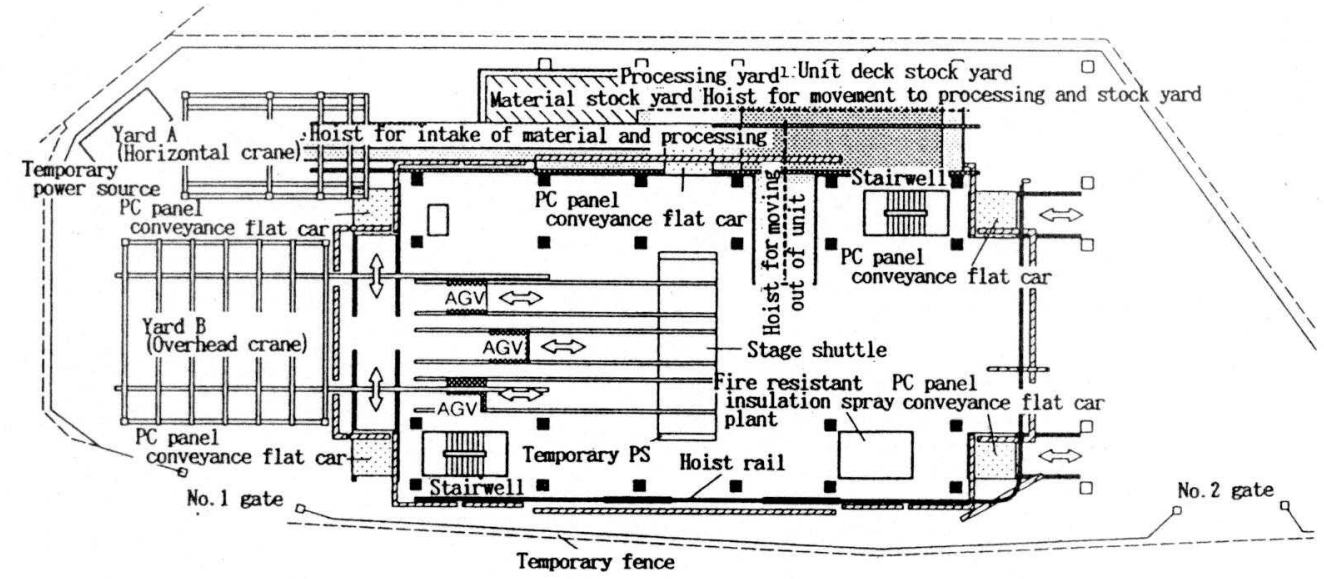

Fig.6. Layout plan of ground factory

(1) AGV (Automatic Guided Vehicle)

AGV receives 4 types of steel structural members, that are moved in by truck including columns, girders, beams and staircases via an overhead travelling crane that is installed above the moving in yard. It carries them from the ground factory to the sky factory. There are 3 types of AGV prepared, namely an AGV for the conveyance of columns, an AGV for the conveyance of girders and an AGV for conveyance of beams.

The AGV for the conveyance of columns has the function of making the steel column lay flat or stand upright. This makes it possible to convey the steel columns laying flat and later it is possible to change the posture to an upright position on the servicing floor.

Photo 2 shows the AGV for the conveyance of columns in the condition of being loaded with a steel column.

AGV for the conveyance of girders has the function of turning the steel girder loaded on it and makes it possible to be loaded on the transfer line 
by turning the long size steel girder in the ground factory. Photo 3 shows the AGV for the conveyance of girders in the condition where it is loaded with a steel girder.

AGV for the conveyance of beams can carry 3 steel beams on the loaded rack and conveys them to the destination efficiently. Photo 4 shows the AGV or conveyance of beams in the condition where it is loaded with a steel beam.

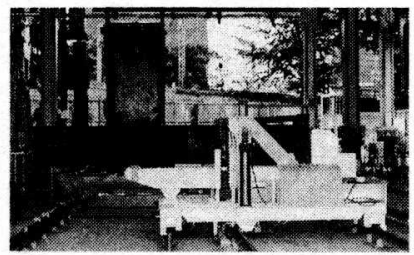

Photo 2. AGV (column)

(2) UNIT DECK PROCESSING YARD

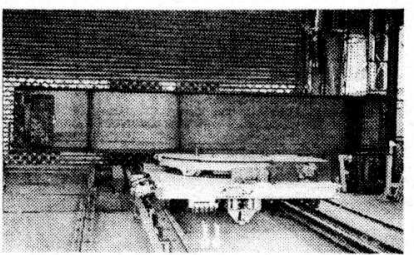

Photo 3. AGV (girder)

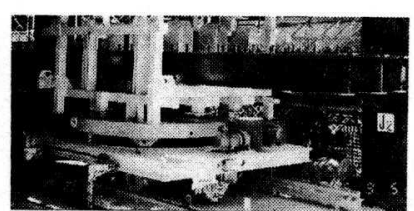

Photo 4. AGV (beam)

The unit deck processing yard is a space where the composite deck is unitized by making members larger. It provides a processing yard for exclusive use in the ground factory and a place for the processing of the interface portion of columns and girders, by installing steel bars and ceiling inserts, etc. It is a place where all of these parts can be preassembled and stored.

It is planned so that in the processing yard, a processing rack and a motordriven hoist are provided for exclusive use in order for the processing operation to proceed smoothly.

Photo 5 shows the situation of the processing of the unit deck.

(3) HORIZONTAL CONVEYANCE DEVICE FOR EXTERIOR PC PANEL

It is a system to convey the exterior PC panel horizontally to directly below the designated position of installation. The conveyance system is planned such that it takes into consideration the site boundary in all four directions, the design configuration of the building and the moving in and processing of construction materials.

- East face : as the boundary of the site leaves a narrow space adjacent to the road, the PC panel received on the north face is horizontally conveyed by the hoist.

- West face : PC panel is lifted by the overhead travelling crane to the height of the second floor and loaded on a travelling flat car for horizontal conveyance.

- South face : horizontally conveyed loading on the travelling flat car.

- North face : horizontally conveyed by the hoist.

The reentrant portion of each face is pulled in loaded on the travelling flat car. Photo 6 shows the situation of horizontal conveyance on the west face.

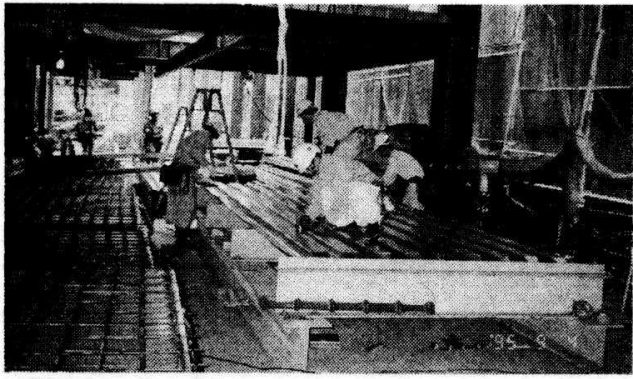

Photo 5. Situation of processing of unit deck

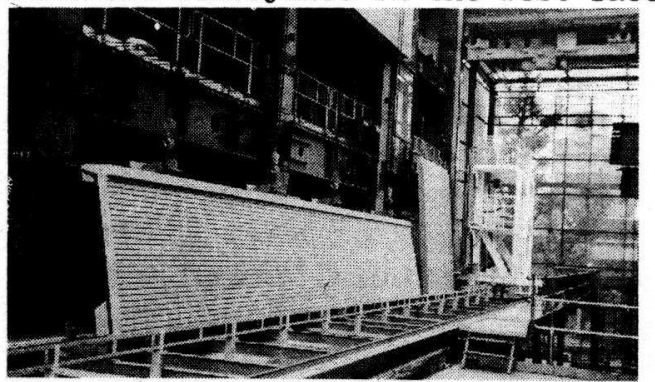

Photo 6. Situation of the horizontal conveyance of the exterior PC panel 
(4) OTHER EQUIPMENT PROVIDED IN THE GROUND FACTORY

As equipment to supply materials for structural work, there is a carbon dioxide supply device for the welding operation support system that is provided in the sky factory, a concrete piping system, and a fire resistant insulation automatic spray plant, etc.

As the finish materials are delivered in various packing shapes, the basic goods handling will be done in the ground factory by means of a forklift.

\section{2 TRANSFER LINE}

The main role played by the transfer line is to receive structural materials and finish materials conveyed horizontally in the ground factory and vertically convey them and supply them automatically to the servicing floor appropriately.

The main component device of the transfer line is a stage shuttle. The stage shuttle is a large automatic lift for the conveyance of large size structural members, such as steel columns, steel girders, etc. These items are loaded on the AGV together with finish materials in various packing shapes and are carried from the ground factory to the sky factory, or to a floor on the way up, through operations in the control room.

The size of the stage is $3.5 \mathrm{~m} \times 11 \mathrm{~m}$ and it has the loading capacity of a 10 ton maximum. The stage is equipped with 4 units of elevator jacks, which can be freely set at a height of up to $1 \mathrm{~m}$ and has functions which allow it to be able to cope with various packing shapes of materials to be conveyed and the transfer of equipment which is to be moved in.

on the first floor, for the protection of openings an automatic shutter is provided, which interlocks with the operations of the AGV and the stage shuttle. This is planned to carry out the automatic vertical conveyance safely.

Photo 7 shows the external appearance of the stage shuttle.

\section{3 SKY FACTORY}

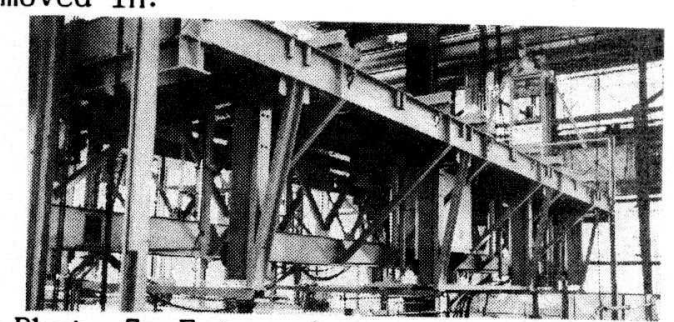

Photo 7. External apperrance of stage shuttle

The main roles played by the sky factory include the role of performing assembly of structural members conveyed from the ground factory by the stage shuttle and to perform the function of conveying the exterior PC panel vertically by electric chain block. This role to provides a comfortable weather-unaffected working space and has the role of performing the control management of each automated device and performing information management of movement in and out of the site intensively. The main equipment in the sky factory is described below.

Firstly, the layout plan of the machine room (16F), which accommodates driving units of main equipment in the sky factory and measurement instruments, etc., is shown in fig. 7 and the internal appearance of the assembling floor of structural members is shown in Photo 8.

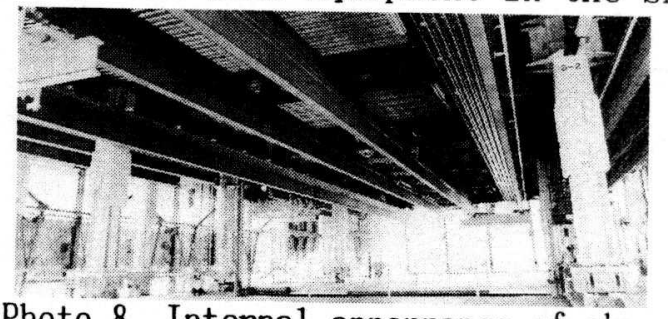

Photo 8. Internal apperrance of sky factory 


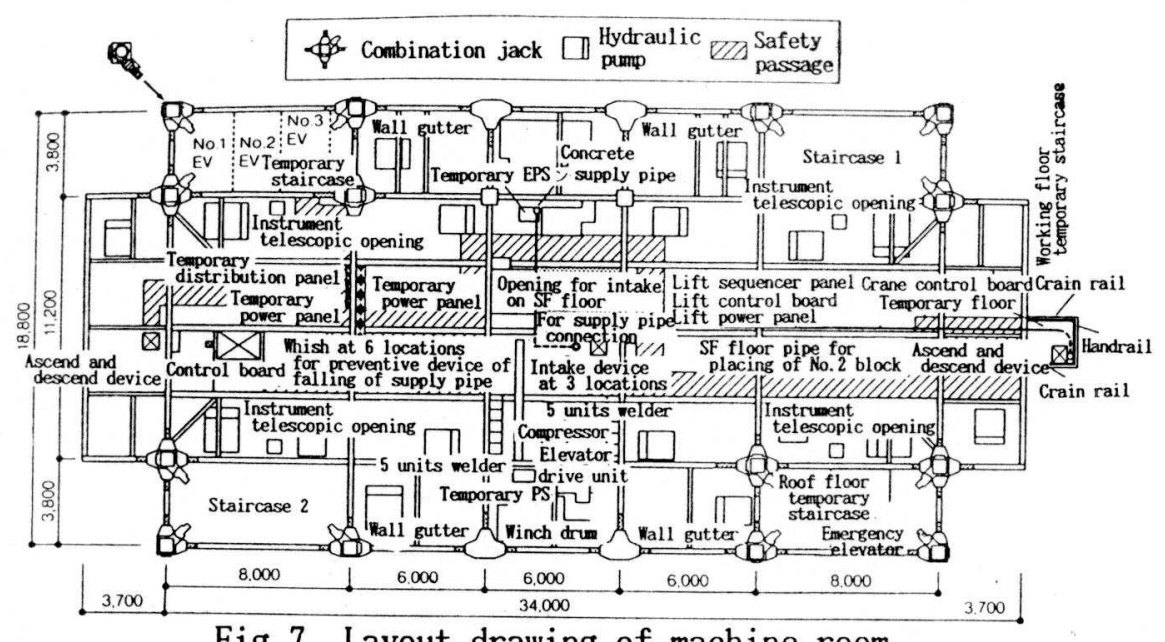

(1) COMBINATION JACK

Fig. 7. Layout drawing of machine room

The combination jack is a device which is used to support the whole of the sky factory and pushes it upward. It is a new composite type high performance jack, which has the merits of the worm gear jack that can be controlled highly accurately and the hydraulic jack that can obtain a large pushing force in combination. The maximum thrust is 120tons and it has the capacity of thrusting up at the speed of a maximum of $60 \mathrm{~mm} / \mathrm{min}$ and it is possible to perform the synchronized control of several tens of jacks with the accuracy of less than $1 \mathrm{~mm}$.

At the lower end of the combination jack a column gripper is installed so that if the pulling force should be applied on the jack during construction it would be counteracted successfully.

Photo 9 shows the external appearance of the combination jack.

(2) UMBRELLA UNIT

The umbrella unit is the one that plays the role of an umbrella for the fully automated building construction system with the weather-unaffected function. It secures working space for installation of the exterior PC panel and working scaffold for the portion facing the perimeter and it is equipped with a protective function for scattering and falling. On the upper part of the umbrella unit (roof top and penthouse floor) there is the permanent concrete floor which has already been placed at the time of structuring the sky factory. On the wall surface a permanent PC panel is used and its function is ended by bringing it around to the position of installation upon the completion of structural work.

Fig. 8 shows the section of the umbrella unit.

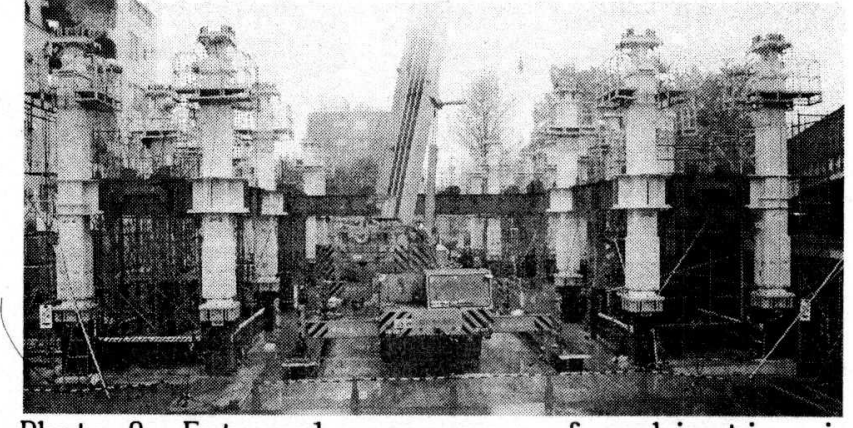

Photo 9. External apperrance of combination jack

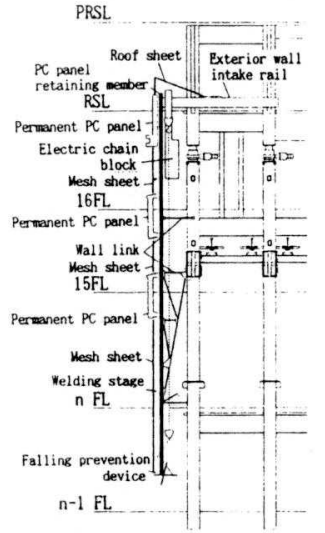

Fig. 8. Section of umbrella unit 
(3) TROLLEY BUS AND TRAVERSER

The main assembling work of one floor structural unit in the sky factory is accomplished by automated operations using 2 units of trolley buses and 5 units of traversers. The trolley bus is a multi-functional robot of ceiling rail travelling type that automatically performs a series of structural construction work from the erection of steel columns, steel girders, steel beams and staircases, to the laying of unit deck, the placing, levelling and surface finishing of concrete and the installation of the utility vertical piping unit, etc., while changing various attachments.

The traverser plays the role of a travelling rail to let the trolley bus travel in the optional direction of $X-Y$ in concert with each other.

Using the combination of the trolley bus and traverser, handling of heavy materials, which was considered difficult before this, became possible so that heavy materials, such as structural steel can be moved to the designated location of installation accurately.

Photos 10, 11, 12, 13, 14 and 15 show the situation of steel columns, steel girders, steel beams, unit decks, concrete placing/levelling device and utility vertical piping units that are being gripped by the trolley bus.

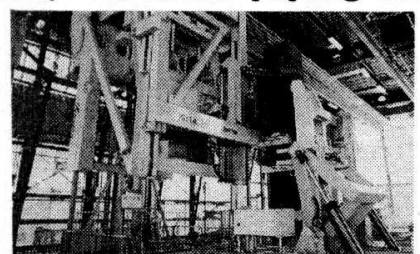

Photo 10. Steel column

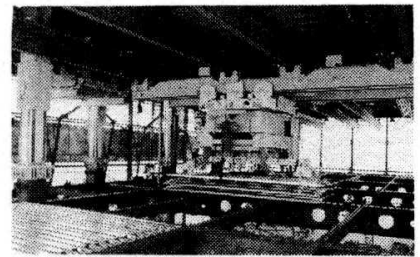

Photo 13. Unit deck

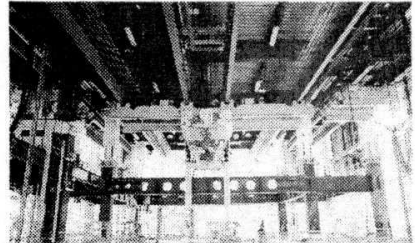

Photo 11. Steel girder

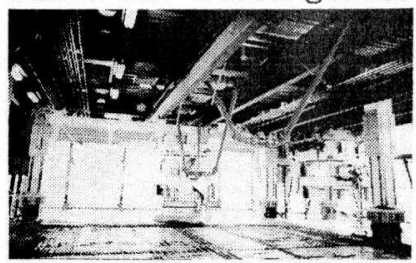

Photo 14. Concrete

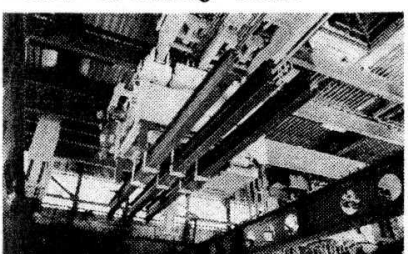

Photo 12. Steel beam

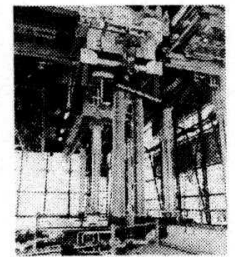

Photo 15. Piping unit

(4) VERTICAL CONVEYANCE DEVICE OF THE EXTERIOR PC PANEL

The vertical conveyance device of the exterior PC panel is composed of a plural number of electric chain blocks that are installed in the umbrella unit, and each chain block has the lifting height of $80 \mathrm{~m}$. The exterior PC panel (maximum 5ton) is vertically conveyed by controlling 2 units of electric chain blocks simultaneously and is installed on the perimeter of one floor below the servicing floor. Photo 16 shows the situation of exterior wall being installed using the vertical converyance device of an exterior PC panel.

(5) MAIN COLUMN WELDING ROBOT

It is a welding robot that can be moved readily within the site. It is set on the main steel column after an initial layer has already been completed and the welding work by the fully automated robot is commenced. As a series of operations, from sensing of beveling, removing of slug to nozzle cleaning can be performed automatically, the continuous multi-layer automated welding work becomes possible. Photo 17 shows the main steel column welding robot.

(6) FIRE RESISTANT INSULATION SPRAY ROBOT

The fire resistant insulation spray robot performs the work on the floor 3 or 4 floors below the servicing floor of the sky factory. On the self-travelling 
flat car, equipped with a light-weight manipulator sold on the market, a sensor to recognize self-position is installed. The spray operations are then carried out automatically while controlling the fully-automated plant that is installed in the ground factory. Photo 18 shows the fire resistant insulation spray robot.

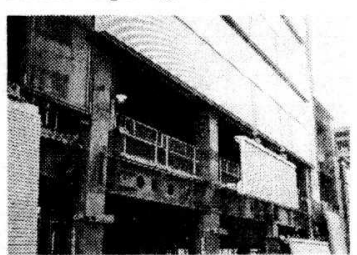

Photo16. Situation of exterio wall being installed

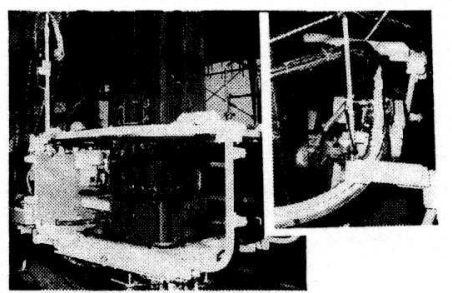

Photol7. Main steel colum welding robot

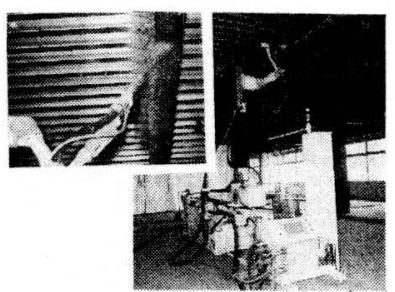

Photo18. Fire resistant insulation spray robot

(7) HORIZONTAL AND VERTICAL ACCURACY MEASUREMENT DEVICE

It is a measurement device which maintains the position of the sky factory with a high accuracy to construct a high quality structure. It performs vertical measurement using a laser beam (invisible rays) and distance measurement using 1 ight waves. Photo 19 shows the external appearance of the upper part of the horizontal and vertical accuracy measurement device, which can be expanded and contracted in a telescopic manner from the machine room to the servicing floor surface.

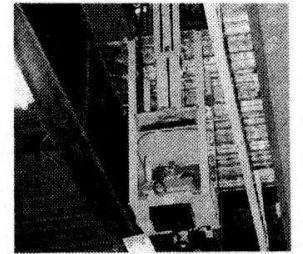

Photo 19. Upper part of the accuracy measurement device

\subsection{CONTROL ROOM}

The control room can be said to be the location of the brain of the weatherunaffected building automated construction system. This is where the control management of each automated device and the information management in and out of the site are intensively performed. The trained operator undertakes handling and operation exclusively and by means of sensors installed on each automated device and by utilizing the ITV synthetic monitoring system. The control management of each automated device, namely combination jack, trolley bus, traverser, stage shuttle, AGV, electric chain block, etc., can move forward safely.

In addition, as the system aims at realizing multi-media operation by introducing a satellite circuit communication system, the information communication from the location away from the site can be taken. Photo 20 shows the internal appearance of the control room.

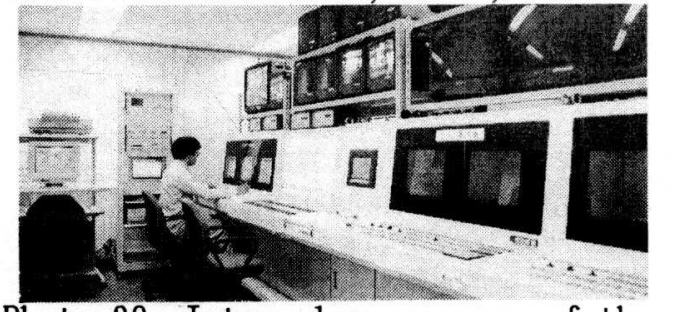

Photo 20. Internal appearance of the control room

\section{SITUATION OF SYSTEM BEING APPLIED TO THE SITE}

Assembling of the sky factory commenced in the latter part of April this year and the first jack up was performed in the latter part of June. This is when the construction of the first floor started. The work has been in progress in line with the initial plan and in accordance with the cycle 
schedule of 8 days as shown in Fig. 9. The main schedule of the cycle includes the erection of the structural steel, welding and tightening between Day 1 to Day 4, laying of floor deck and floor utility piping between Day 5 to Day 6, concrete placing on Day 7 and jack up on Day 8. In the latter part of December, it is scheduled to commence dismantling of the ground factory and the sky factory and most of the machine devices will have been removed by February next year.

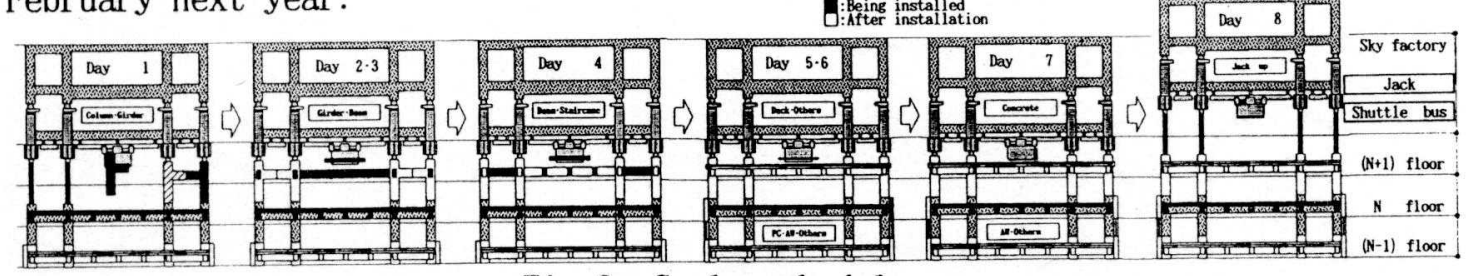

Fig. 9. Cycle schedule

During the initial period after commencing construction using this system, it tended to be behind schedule in proceeding with one cycle of operations. Particularly, the construction between the first and third cased confusion among workers because of the different work procedure and scope of responsibility compared with the conventional method of construction. In addition, various troubles occurred in the development of the machine device and there were deficiencies, in the plan due to the difference of floors from a typical floor. This was the period that caused the most trouble for all people concerned.

However, when the time came to perform the construction of typical floors from above the fourth floor, the progress of the work improved rapidly. The workers were at ease with operations within the cycle and there was a sharp decrease in problems with the machine device. Neither could deficiencies in the plan be seen. Although the construction cycle proceeded with difficulty in the construction ability in both men and machine, the emphasis of the cycle has now been shifted to confirm whether or not construction materials would be moved in as scheduled. At the present stage, the number of workers for structural work is reduced by $2 / 3$ to $1 / 2$ compared with in the beginning and in fact there appeared to be some trades that took one additional holiday in the cycle in addition to the scheduled one.

\section{CONCLUSIONS}

Now that construction using this system has come to the stage where only dismantling of machine devices and finish work are remaining, all persons concerned are determined to carry out work prudently so as to be able to see the completion without accident.

With respect to the construction results, we are now starting to analyze numerous construction data collected thus far as the sky factory has reached the design height. The analysis will be made from various points of view, such as quality, cost, schedule, safety, etc., and we hope to understand the effectiveness of the weather-unaffected building construction system qualitatively.

By reflecting on the experience of construction obtained this time, the next application plan will aim at structuring a better weather-unaffected building constructin system. 